Revista Temas Socio Jurídicos

Vol. 37 No 74 Enero - Junio de 2018

pp. $33-67$

ISSN: 0120-8578

ISSN electrónico: 2590-8901

\title{
LA GLOBALIZACIÓN DE LOS DERECHOS DEL NIÑO: EL CORPUS JURIS INTERAMERICANO Y SU CONTROL DE CONVENCIONALIDAD EN MATERIA DE VIOLENCIA INTRAFAMILIAR
}

\author{
Aida Elia Fernández De Los Campos ${ }^{1}$ \\ Recibido: Abril 23 de 2018 \\ Aprobado: Mayo 31 de 2018
}

\section{RESUMEN}

El presente artículo tiene como finalidad analizar los derechos humanos de niños y niñas a partir del corpus juris de los derechos humanos; en especial, en los componentes que, en el ámbito internacional, desarrollan la protección de los menores de edad frente a la violencia intrafamiliar.

Palabras clave: derechos humanos, niños, violencia intrafamiliar, derecho internacional.

\section{CHILDREN'S RIGHTS GLOBALIZATION: THE INTER-AMERICAN CORPUS JURIS AND ITS CONVENTIONALITY CONTROL IN THE MATTER OF DOMESTIC VIOLENCE}

\footnotetext{
ABSTRACT

This paper has as purpose to analise the children's human rights starting at

1 Doctora en Derechos humanos y desarrollo de la Universidad Pablo de Olavide de Sevilla, España. Magistra en Derecho de familia de la Universidad Autónoma de Bucaramanga (UNAB), Bucaramanga, Colombia. Especialista en Globalización y procesos de integración en Europa, Fundación Universidad Carlos III, España. Especialista en Problemas actuales de los Derechos fundamentales, Fundación Universidad Carlos III, España. Doctora en Derecho y Ciencias Sociales y doctora en Diplomacia, Universidad de La República, Uruguay.
} 
the corpus juris of human rights; specially, regarding to those components that, in the international sphere, develope protection of minors against domestic violence.

Keywords: Human Rights, Children, Domestic violence, International law.

\section{A GLOBALIZAÇÃO DOS DIREITOS DA CRIANÇA: O CORPUS JURIS INTERAMERICANO E SEỦ CONTROLE DE CONVENCIONALISMO SOBRE VIOLENCIA INTRAFAMILIAR}

\section{RESUMO}

O objetivo deste artigo é analisar os direitos humanos das crianças baseado no Corpus Juris dos direitos humanos e, em particular, nos componentes que, no âmbito internacional, desenvolvem a proteção dos menores contra a violência intrafamiliar.

Palavras-chave: direitos humanos, crianças, violência intrafamiliar, direito internacional.

\section{INTRODUCCIÓN}

Este texto aborda el corpus juris de los derechos humanos del niño, con especial énfasis en los instrumentos jurídicos internacionales del sistema regional interamericano que promueven la erradicación de la violencia intrafamiliar en la niñez y adolescencia. Esto, con el fin de resaltar el papel de dichas herramientas de interpretación para la adecuación de la normatividad interna de los Estados a los estándares internacionales.

Para desarrollar el tema planteado, en la primera parte, se abordan los conceptos niño y violencia intrafamiliar; sobre esta, se estudian sus consecuencias, incluyendo la tensión que desencadena entre las dimensiones de lo público y lo privado. En la segunda parte, se presenta el corpus juris de los derechos del niño, de alcance universal y regional interamericano. En la tercera parte, se hace referencia a la adecuación de las normas jurídicas internas al sistema interamericano de protección de los derechos humanos mediante el control de convencionalidad.

\section{CONCEPTOS}

\section{1. ¿Qué es el niño?}

En este trabajo se parte del concepto de niño ${ }^{2}$ desde un enfoque de derechos. Se hace referencia a todo ser humano menor de dieciocho años, 
titular activo de derechos, tal como reivindica con autonomía Galvis (2006, pp.66 y 67), con base en los lenguajes que maneja según la etapa de su desarrollo ${ }^{3}$. La garantía de sus derechos es el cumplimiento del deber primario que tienen sus padres para asegurar la gestión autónoma de su vida, en la dimensión de la libertad y del ejercicio responsable de esos derechos. De esto, se sigue que la titularidad de los derechos no está condicionada, en su origen y capacidad, a los ordenamientos jurídicos; estos son la garantía del ejercicio de los derechos humanos para todas las personas, cualquiera que sea la etapa del ciclo vital en que se encuentren (p.175 y ss.).

La titularidad de los derechos de los niños, que alcanza su máxima expresión en la Convención sobre los Derechos del Niño de 1989, es universal, tanto en el reconocimiento y en el ejercicio, como en el restablecimiento de sus derechos cuando estos son violados, como sucede cuando son víctimas de violencia intrafamiliar. Esta concepción es el resultado de un proceso de diferenciación de los niños respecto a los adultos y refleja las transformaciones sociales que en cada momento de la historia se han operado: de una larga etapa de negación de sus derechos hasta su reconocimiento. Tales derechos son indivisibles, interdependientes y todos igualmente importantes, de modo que deben ser protegidos y garantizados de manera integral y en forma solidaria, conjunta y simultánea (Galvis, 2006).

A pesar de los avances alcanzados en cuanto a la especificidad del mundo de los niños como un espacio de ejercicio de autonomías y de respeto entre iguales, este grupo poblacional sigue siendo víctima de flagelos como la violencia. Esta, según el Informe anual de la Representante Especial del Secretario General sobre la violencia contra los niños (2016), afecta a millones de niños en todo el mundo, de todas las edades, en sus barrios, sus escuelas, en las instituciones encargadas de cuidarlos y protegerlos y también en sus hogares ${ }^{4}$.

\subsection{La violencia intrafamilia}

3 Con base en lo expuesto por Hanna Arendt (1974), los derechos humanos deben ser comprendidos como un proceso constante de construcción de ciudadanía, que se expresa en el reconocimiento del "derecho a tener derechos".

4 Entre los esfuerzos de la comunidad internacional por promover un entorno en el que los niños vivan sin violencia, se destacan La Iniciativa Global para Acabar con todo Castigo Corporal hacia los niños, lanzada en el 2001 y administrada por la Asociación para la Protección de Todos los Niños, el enfoque Ltd. Se puede visitar su sitio web en http://www. endcorporalpunishment.org/prohibiting-corporal-punishment/introduction.html.

Asimismo, se debe mencionar la Campaña del Fondo de Naciones Unidas para la Infancia (UNICEF) \#ENDviolence, implementada en el año 2013 y disponible en https://www.unicef. org/spanish/endviolence/.

También, en el año 2015, Save the Children inició la campaña "No quieres que te vean así" para América Latina y el Caribe. Esta se puede consultar en https://resourcecentre. savethechildren.net/library/changing-attitudes-no-quieres-que-te-vean-asi. 
La violencia ${ }^{5},{ }^{6}$ se expresa de múltiples maneras; entre ellas, la intrafamiliar. Esta aparece como un emergente de la vida cotidiana, que puede conceptualizarse como el estilo de vínculo que obstaculiza e impide el desarrollo de las potencialidades y capacidades humanas requeridas para la realización de los derechos de sus miembros. Corsi (1997) señala que el término violencia intrafamiliar alude a las formas de relación abusiva que caracterizan de modo permanente o cíclico las que tienen lugar al interior de las familias ${ }^{7}$ y obedece a la confluencia de múltiples factores ${ }^{8}$ (p.31).

1.2.1. Consecuencias de la violencia intrafamiliar. El Comité de los Derechos del Niño, en la Observación General No.13 (2011), Derecho del niño a no ser objeto de ninguna forma de violencia, destaca que: "Los costos humanos, sociales y económicos de denegar a los niños su derecho a la protección son ingentes e inaceptables" (párr.16). Asimismo, el Informe anual de la Representante Especial del Secretario General sobre la violencia contra los niños (2016) expresa que:

La violencia compromete todos los derechos de los niños. Va de la mano de la vulnerabilidad y las privaciones, además de un riesgo elevado de padecer problemas de salud, bajo rendimiento escolar y dependencia a largo plazo del sistema de asistencia social. En la primera infancia, los efectos de la violencia son a menudo irreversibles. A medida que crece el niño, la exposición acumulativa a las manifestaciones de violencia se convierte en una triste constante que se prolonga durante toda la vida y a veces persiste a través de varias generaciones.

Más allá del perjuicio a cada víctima y a su familia, la violencia trae

5 La raíz del término violencia, vis, significa fuerza, lo cual implica que la violencia constituye el uso de la fuerza para someter, doblegar, subordinar. En sentido amplio, se puede hacer referencia a la violencia política, social, económica, física y psicológica, la cual, en sus múltiples expresiones, entraña el ejercicio del poder mediante el empleo de la fuerza. En sentido restringido, se alude a las conductas violentas, las cuales se hacen posibles en un contexto de desequilibrio de poder, permanente o momentáneo, que supone la existencia de un arriba y un abajo: padre-hijo, hombre-mujer, maestro-alumno, patrón-empleado, joven-viejo.

6 Existen enfoques que consideran la violencia como una conducta omnipresente e inevitable. Tales enfoques se encuentran en las ideas de Charles, Sigmund Freud y, de sus seguidores, la explicación de su creencia. Otros sostienen que se trata de un comportamiento aprendido, que se desarrolla a medida que el ser humano se relaciona con su entorno, con base en los postulados de Albert Bandura y Luis Rojas Marcos, entre otros.

7 Las familias que hacen uso del golpe o el insulto para resolver sus diferencias han fracasado en sus intentos de diálogo y en la formulación de alternativas para lograr el mutuo acuerdo.

8 El modelo ecológico propuesto por Urie Bronfenbrenner (1998) postula que la realidad familiar, la realidad social y la cultural están organizadas como un todo, como un sistema compuesto por diferentes subsistemas que se articulan entre sí de manera dinámica. En este sentido, se distingue del macrosistema (creencias culturales asociadas a la violencia intrafamiliar), el exosistema (constituido por los espacios que conforman el entorno social visible en el que se desenvuelve la familia y comprende la legitimación institucional de la violencia), el microsistema (donde se agrupan las estructuras familiares de corte autoritario) y el nivel individual (ámbito en el que se identifican las dimensiones cognitiva, conductual, psicodinámica e interaccional). 
consigo costos trascendentales para la sociedad. La violencia desvía miles de millones de dólares de la inversión social, ralentiza el desarrollo económico y erosiona el capital humano y social de los Estados. (párrs.22 y 23).

1.2.2. Tensión entre las dimensiones de lo público y privado. La violencia intrafamiliar representa en la actualidad un problema social, cuyo reconocimiento pone en tela de juicio la tradicional privacidad de la familia (Fernández, 2010, p.98). En la actualidad, con base en lo expresado en el Informe sobre el Castigo Corporal y los Derechos Humanos de las niñas, niños y adolescentes de la Relatoría de la Niñez de la Comisión Interamericana de Derechos Humanos (2009), se dice que:

El Derecho Internacional de los Derechos Humanos ${ }^{9}$ no admite argumentaciones basadas en la dicotomía de lo público y lo privado, que tienden a desconocer o restringir injustificadamente los derechos humanos". La CIDH señala en este mismo documento que "los tribunales y los órganos de supervisión internacional de los derechos humanos han subrayado la importancia de la naturaleza erga omnes de las obligaciones de los Estados de respetar y hacer respetar el derecho de los niños a tener una protección especial incluso en el ámbito privado. (párr.69).

La violencia intrafamiliar implica la vulneración de los derechos humanos de quienes la padecen; por consiguiente, justifica la irrupción en el seno de la familia ${ }^{10} \mathrm{y}$, al mismo tiempo, el cuestionamiento del vínculo existente entre la víctima y el victimario, como el que tiene lugar en la relación paternofilial, a pesar de los derechos y deberes legitimados mediante la responsabilidad parental, institución normalizadora de las relaciones familiares.

\section{EL CORPUS JURIS INTERNACIONAL DE PROTECCIÓN DE LOS DERECHOS HUMANOS DEL NIÑO RESPECTO A LA VIOLENCIA INTRAFAMILIAR}

La evolución del Derecho Internacional de los derechos humanos ha dado

\footnotetext{
9 El Preámbulo de la Declaración Universal de los Derechos Humanos (1948) señala que tanto los individuos como las instituciones, inspirándose constantemente en ella, promueven, mediante la enseñanza y la educación el respeto a estos derechos y libertades.

10 En la Sentencia C-256/08, la Corte Constitucional de Colombia destaca que "la figura del allanamiento con fines de rescate regulado por los artículos 86, numeral 6 y 106 de la Ley 1098 de 2006, se inscribe dentro de la protección del interés superior del menor y en esa medida fue establecida como una medida de naturaleza preventiva, cautelar, orientada a proteger la vida o integridad personal, pero en virtud de que solo un peligro grave y una necesidad imperiosa autorizan el régimen excepcional bajo el cual ciertas autoridades administrativas pueden realizar allanamientos [...]".
} 
lugar a la existencia de un corpus juris ${ }^{11}$ de protección de los derechos del niño, que se fundamenta en su reconocimiento como sujeto de derecho. La Corte Interamericana de Derechos Humanos ha establecido que "el corpus juris ${ }^{12}$ del Derecho Internacional de los Derechos Humanos ${ }^{13}$ está formado por un conjunto de instrumentos de contenido y efectos jurídicos variados (tratados, resoluciones y declaraciones)" de alcance universal y regional, además de las observaciones formuladas por los órganos internacionales de protección de los derechos humanos e informes de expertos independientes, de relatores especiales y de grupos de trabajo.

Este avance evidencia la existencia de un marco jurídico común en el Derecho Internacional de los Derechos Humanos y la interdependencia que existe en el ámbito internacional entre los distintos sistemas internacionales de protección de derechos ${ }^{14}$. A continuación se presentan el corpus juris de alcance universal y los instrumentos interamericanos.

\subsection{El corpus juris universal}

El corpus juris universal se relaciona con la protección de los derechos del niño contra actos de violencia intrafamiliar y tiene vigencia en Colombia. Está conformado por tratados, resoluciones, observaciones generales de los órganos encargados del monitoreo de los convenios y recomendaciones, además contiene el Informe de las Naciones Unidas sobre Violencia contra los Niños, Niñas y Adolescentes y los reportes anuales de la Representante Especial del Secretario General sobre la violencia contra los niños.

2.1.1. El ordenamiento jurídico de alcance universal. El cuerpo normativo de alcance universal se encuentra en las Declaraciones sobre

\footnotetext{
11 La Corte Interamericana de Derechos Humanos manifestó la existencia de un corpus juris de los derechos humanos del niño en el año 1999, Caso de los "Niños de la Calle" (Villagrán Morales y otros) (Sentencia de 19 de noviembre de 1999. Serie C No. 63, párr.194). Al respecto, ha señalado que "tanto la Convención Americana como la Convención sobre los Derechos del Niño forman parte de un muy comprensivo corpus juris internacional de protección de los niños que debe servir a esta Corte para fijar el contenido y los alcances de la disposición general definida en el artículo 19 de la Convención Americana" (Corte I.D.H., Condición Jurídica y Derechos Humanos del Niño. Opinión Consultiva OC-17/02 de 28 de agosto de 2002. Serie A No. 17, párrs.37 y 53).
}

12 La expresión "corpus juris de los derechos humanos" es un aporte de la Corte IDH a la doctrina internacional.

13 Corte I.D.H., OC-16, El Derecho a la información sobre la asistencia consular en el marco del debido proceso, 1 de octubre de 1999, párr.115.

14 En los últimos años se ha producido un fortalecimiento del diálogo judicial en el ámbito de los tribunales internacionales de derechos humanos. Al respecto, se puede consultar el DIÁLOGO TRANSATLÁNTICO: SELECCIÓN DE JURISPRUDENCIA DEL TRIBUNAL EUROPEO Y LA CORTE INTERAMERICANA DE DERECHOS HUMANOS (2015). Asimismo, la Corte Interamericana de Derechos Humanos, para dotar de alcance y contenido a los derechos humanos consagrados en los tratados del sistema interamericano, recurre a otros tratados internacionales, a los pronunciamientos de los órganos de los tratados de Naciones Unidas, a los procedimientos especiales del Consejo de Derechos Humanos de la ONU y a normas de soft law. 
los Derechos del Niño de $1924^{15}$ y $1959^{16}$, en la Carta Internacional de Derechos Humanos - la Declaración Universal de Derechos Humanos ${ }^{17} \mathrm{y}$ los dos Pactos Internacionales, el de Derechos Civiles y Políticos ${ }^{18}$ y el de Derechos Económicos, Sociales y Culturales de $1966^{19}$, la Convención sobre la Eliminación de todas las Formas de Discriminación contra la Mujer de 1979 y el Protocolo Facultativo,

15 El artículo primero expresa: "El niño debe ser puesto en condiciones de desarrollarse normalmente desde el punto de vista material y espiritual".

16 El Principio 2 señala que "el niño gozará de una protección especial y dispondrá de oportunidades y servicios, dispensado todo ello por la ley y por otros medios, para que pueda desarrollarse física, mental, moral espiritual y socialmente en forma saludable y normal, así como en condiciones de libertad y dignidad. Al promulgar leyes con este fin, la consideración fundamental a que se atenderá será el interés superior del niño”. El Principio 6 agrega "El niño para el pleno y armonioso desarrollo de su personalidad, necesita amor y comprensión. Siempre que sea posible, deberá crecer al amparo y bajo la protección de sus padres y, en todo caso, en un ambiente de afecto y de seguridad moral y material [...]" Y el Principio 9 dispone que "el niño debe ser protegido contra toda forma de abandono, crueldad y explotación [...]”.

17 Este texto dispone en el preámbulo: “[...] Considerando que los pueblos de las Naciones Unidas han reafirmado en la Carta su fe en los derechos fundamentales del hombre, en la dignidad y el valor de la persona humana y en la igualdad de derechos de hombres y mujeres, y se han declarado resueltos a promover el progreso social y a elevar el nivel de vida dentro de un concepto más amplio de la libertad [...]. Considerando que los Estados Miembros se han comprometido a asegurar, en cooperación con la Organización de las Naciones Unidas, el respeto universal y efectivo a los derechos y libertades fundamentales del hombre". En el artículo 5 expresa que "nadie será sometido a torturas ni a penas o tratos crueles, inhumanos o degradantes". En el artículo 8 establece que "toda persona tiene derecho a un recurso efectivo ante los tribunales nacionales competentes, que la ampare contra actos que violen sus derechos fundamentales reconocidos por la constitución o por la ley”.

18 El preámbulo hace referencia a que: "el reconocimiento de la dignidad inherente y de la igualdad de sus derechos inalienables de todos los miembros de la familia humana es el fundamento de la libertad, la justicia y la paz en el mundo [...]". El artículo 7 establece que "nadie debe ser sometido a torturas o a un tratamiento cruel, inhumano y degradante o castigo [...]". Asimismo, el artículo 24 (1) establece que "todo niño debe tener, sin discriminación sobre la base de la raza, color, sexo, lenguaje, religión, nacionalidad u origen social, propiedad o nacimiento, el derecho a disfrutar de todas las medidas de protección tal como lo demanda su estatus de "menor", dentro de la familia, la sociedad y el estado".

19 Este Pacto reitera, en el Preámbulo, lo expresado en el Pacto Internacional de Derechos Económicos, Sociales y Culturales, el reconocimiento de la dignidad inherente y de la igualdad de los derechos inalienables de todos los miembros de la familia humana. Además, el artículo 10 (3) agrega que "medidas especiales de protección y asistencia deben ser tomadas por el bienestar de los niños y las personas jóvenes, sin lugar a discriminación sobre la base de parentesco u otras condiciones $[. .$.$] ".$ 
además de la Convención sobre los Derechos del Niño de 1989²0, sus Protocolos Facultativos y la Declaración sobre la Eliminación de la Violencia contra la Mujer de 1994.

Asimismo, para fines de interpretación de los derechos humanos de los niños, es preciso tomar en consideración las Reglas Mínimas de las Naciones Unidas para la Administración de Justicia de Menores (Reglas de Beijing de 1985), las Reglas sobre Medidas No Privativas de Libertad ( Reglas de Tokio de 1990) y las Directrices de las Naciones Unidas para la Prevención de la Delincuencia Juvenil (Reglas de Riad de 1990), además de los instrumentos internacionales sobre derechos humanos de alcance general.

\subsubsection{Resoluciones de los órganos de la Organización de Naciones} Unidas, la ONU. En cuanto a las resoluciones, son de interés para este trabajo las proferidas por la Asamblea General de la ONU y del Consejo de Derechos Humanos en torno a los derechos del niño.

\subsubsection{Resoluciones de la Asamblea General de la ONU}

Resolución 66/139 de la Asamblea General (2011). Fortalecimiento de la colaboración en materia de protección de los niños dentro del sistema de las Naciones Unidas. Este pronunciamiento resalta la importancia de contar, por parte del sistema de las Naciones Unidas, con recursos y apoyo suficientes y continuos para su labor de promoción y protección de

20 La Convención sobre los Derechos del Niño dispone en el artículo 5: "Los Estados Parte respetarán las responsabilidades, los derechos y los deberes de los padres o, en su caso, de los miembros de la familia ampliada o de la comunidad, según establezca la costumbre local, de los tutores u otras personas encargadas legalmente del niño de impartirle, en consonancia con la evolución de sus facultades, dirección y orientación apropiadas para que el niño ejerza los derechos reconocidos en la presente Convención”. En el artículo 18.1 establece: "Los Estados Parte pondrán el máximo empeño en garantizar el reconocimiento del principio de que ambos padres tienen obligaciones comunes en lo que respecta a la crianza y el desarrollo del niño. Incumbirá a los padres o, en su caso, a los representantes legales la responsabilidad primordial de la crianza y el desarrollo del niño. Su preocupación fundamental será el interés superior del niño". Asimismo, con base en el artículo 19.1, "los Estados Parte adoptarán todas las medidas legislativas, administrativas, sociales y educativas apropiadas para proteger al niño contra toda forma de perjuicio o abuso físico o mental, descuido o trato negligente, malos tratos o explotación, incluido el abuso sexual, mientras el niño se encuentre bajo la custodia de los padres, de un representante legal o de cualquiera otra persona que lo tenga a su cargo. 2. Estas medidas de protección deberían comprender, según corresponda, procedimientos eficaces para el establecimiento de programas sociales con objeto de proporcionar la asistencia necesaria al niño y a quienes cuidan de él, así como para otras formas de prevención y para la identificación, notificación, remisión a una institución, investigación, tratamiento y observación ulterior de los casos antes descritos de malos tratos al niño, y, según corresponda, la intervención judicial”. También son de interés el artículo 37, que dispone que "los Estados Parte velarán, porque: a) Ningún niño sea sometido a torturas ni a otros tratos o penas crueles, inhumanas o degradantes" y el artículo 39, que expresa: "Los Estados Parte adoptarán todas las medidas apropiadas para promover la recuperación física, psicológica y la reintegración social de todo niño víctima de cualesquier forma de abandono, explotación, o abuso, tortura u otra forma de tratos o penas crueles, inhumanos o degradantes [...]. Esa recuperación y reintegración se llevarán a cabo en un ambiente que fomente la salud, el respeto de sí mismo y la dignidad del niño". 
los derechos del niño, incluida la protección de los niños. A este respecto, alienta enérgicamente a que se aumenten las contribuciones voluntarias destinadas a apoyar las actividades de todos los agentes competentes de las Naciones Unidas, a fin de sustentar la asistencia técnica y la creación de capacidad en el ámbito de la protección de los niños.

Resolución 66/170 de la Asamblea General (2011). Día Internacional de la Niña. El texto invita a todos los Estados Miembros, las organizaciones competentes del sistema de las Naciones Unidas y otras organizaciones internacionales, así como a la sociedad civil, a observar el Día Internacional de la Niña y crear conciencia sobre la situación de las niñas en todo el mundo.

Resolución 66/141 de la Asamblea General (2012). Derechos del niño. Este documento constituye un llamado a que los Estados adopten o refuercen, según corresponda, las medidas legislativas y de otra índole con miras a prevenir, prohibir y eliminar con eficacia todas las formas de violencia contra los niños, en todos los contextos.

Resolución 67/152 de la Asamblea General (2012). Derechos del niño. Por medio de este instrumento, la Asamblea General insta a todos los Estados, solicita a las entidades y organismos de las Naciones Unidas e invita a las organizaciones regionales y a la sociedad civil, incluidas las organizaciones no gubernamentales, a que cooperen con la Representante Especial del Secretario General sobre la Violencia contra los Niños, para impulsar la aplicación de las recomendaciones del estudio de las Naciones Unidas sobre la violencia contra los niños. Además, alienta a los Estados a que presten apoyo a la Representante Especial suficiente apoyo financiero de carácter voluntario, para que siga desempeñando de forma eficaz e independiente su mandato establecido en la resolución 62/141, e invita al sector privado a que haga contribuciones voluntarias a este fin.

\subsubsection{Resoluciones del Consejo de Derechos Humanos}

Resolución 19/37 del Consejo de Derechos Humanos. Derechos del niño. La Resolución del año 2012 alienta a los Estados a poner en práctica las recomendaciones formuladas en el estudio de las Naciones Unidas sobre la violencia contra los niños. Para ello, aprovecha el proceso de seguimiento promovido por la Representante Especial del Secretario General sobre la violencia contra los niños y los insta a que den prioridad a la prevención. Su fin es luchar contra la fuerte incidencia y los efectos a largo plazo de todas las formas de violencia contra los niños que tienen lugar en todo el mundo, en el hogar y la familia, en las escuelas y otros centros educativos, en los sistemas de guarda y de justicia, en los lugares de trabajo y en las comunidades. 
2.1.3. Observaciones generales ${ }^{21}$ de los órganos encargados del monitoreo de los convenios de alcance universal. En esta sección se presentan observaciones del Comité de los Derechos del Niño, del Comité de los Derechos Humanos y del Comité de los Derechos Económicos, Sociales y Culturales.

2.1.3.1. Observaciones generales del Comité de los Derechos del Niño. El Comité de los Derechos del Niño ${ }^{22}$ ha emitido las siguientes observaciones generales de interés para este trabajo:

- No. 1 (2001). Párrafo I del Artículo 29: Propósitos de la Educación.

- No. 5 (2003). Medidas generales de aplicación de la Convención sobre los Derechos del Niño (artículos 4 y 42 y párrafo 6 del artículo 44).

- No. 8 (2006). El derecho del niño a la protección contra los castigos corporales y otras formas de castigo crueles o degradantes (artículo 19, párrafo 2 del artículo 28 y artículo 37 , entre otros).

- No. 12 (2009). El Derecho del Niño a ser escuchado.

- No. 13 (2011). Derecho del niño a no ser objeto de ninguna forma de violencia.

- No. 14 (2013). El derecho del niño a que su interés superior sea una consideración primordial (artículo 3, párrafo 1).

- No. 15 (2013). sobre el derecho del niño al disfrute del más alto nivel posible de salud. (art.24).

Asimismo, es pertinente agregar a esta lista la Recomendación general núm. 31 del Comité para la Eliminación de la Discriminación contra la Mujer y observación general Núm. 18 del Comité de los Derechos del Niño sobre las prácticas nocivas (2014), adoptadas de manera conjunta.

Observación General No. 1. Se centra en el Párrafo 1 del artículo 29

\footnotetext{
21En desarrollo de sus funciones, los comités encargados de verificar el cumplimiento de los tratados de derechos humanos, emiten observaciones generales. A diferencia de las observaciones finales, que constituyen un diagnóstico acerca de la situación real del disfrute de los derechos en el Estado que presenta el informe, las observaciones generales interpretan el contenido y alcance de un derecho establecido en la respectiva Convención o Pacto. Estas observaciones se aplican a todos los Estados Parte del tratado, los cuales deben tenerlas en cuenta como pautas para interpretar el alcance y contenido de los derechos y obligaciones consignadas en el mismo (Botero y Guzmán, 2007).
}

22 Encargado de monitorear la aplicación de la Convención sobre los Derechos del Niño. 
de la Convención sobre los Derechos del $\mathrm{Niño}^{23}$ y subraya el papel de la educación en la formación del individuo, respetuoso de los derechos humanos del otro y ajeno a toda manifestación de violencia (Oficina del Alto Comisionado de Naciones Unidas para los Derechos Humanos, 2001). Al respecto el Comité resalta que:

Los conocimientos básicos no se limitan a la alfabetización y a la aritmética elemental sino que comprenden también la preparación para la vida activa, por ejemplo, la capacidad de adoptar decisiones ponderadas; resolver conflictos de forma no violenta; llevar una vida sana, tener relaciones sociales satisfactorias y asumir responsabilidades, desarrollar el sentido crítico, dotes creativas y otras aptitudes que den a los niños las herramientas necesarias para llevar adelante sus opciones vitales. (párr.9).

Observación General No. 5 (2003). En ella, el Comité de los Derechos del Niño señala que, mediante la ratificación de la Convención ${ }^{24}$, los Estados asumen la obligación de aplicarla y, por consiguiente, deben tomar medidas para garantizar la efectividad de todos los derechos humanos reconocidos en el documento para todos los niños situados dentro de su jurisdicción. Para ello, las acciones que se emprendan, en las que están comprendidas aquellas que propendan por poner fin a la violencia contra los niños, deben tomar en cuenta los siguientes principios generales: no discriminación, el interés superior del niño como consideración primordial, el derecho intrínseco del niño a la vida conjuntamente con la obligación de garantizar en la máxima medida posible la supervivencia y el desarrollo del niño y su derecho a expresar libremente su opinión en todos los asuntos que le afecten y a que se tengan debidamente en cuenta esas opiniones (Oficina del Alto Comisionado de Naciones Unidas para los Derechos Humanos, 2003).

Observación General No. 8 (2006). Destaca la obligación de todos los Estados Parte de actuar rápidamente para prohibir y eliminar todos los castigos corporales ${ }^{25} \mathrm{y}$ todas las demás formas de castigo crueles o degradantes a los niños y esbozar las medidas legislativas y otras medidas

23Artículo 29. 1. "Los Estados Parte convienen en que la educación del niño deberá estar encaminada a: [...] b) Inculcar al niño el respeto de los derechos humanos y las libertades fundamentales y de los principios consagrados en la Carta de las Naciones Unidas; [...] d) Preparar al niño para asumir una vida responsable en una sociedad libre, con espíritu de comprensión, paz, tolerancia, igualdad de los sexos y amistad entre todos los pueblos, grupos étnicos, nacionales y religiosos y personas de origen indígena [...]".

$24 \mathrm{Tal}$ como dispone el Derecho internacional Público.

25 Los castigos corporales fueron condenados en diferentes decisiones de la Comisión Europea de Derechos Humanos y fallos del Tribunal Europeo de Derechos Humanos, tales como Tyrer c. el Reino Unido, 1978; Campbell y Cosans c. el Reino Unido, 1982; CostelloRoberts c. el Reino Unido, 1993; A. c. el Reino Unido, 1998. 
educativas y de sensibilización ${ }^{26}$ (párr.2). Además de ser una obligación estatal bajo la Convención de los Derechos del Niño, el abordar y eliminar el castigo corporal hacia los niños en la familia, las escuelas y otros entornos es "una estrategia clave para reducir y prevenir toda forma de violencia en las sociedades" (Oficina del Alto Comisionado de Naciones Unidas para los Derechos Humanos, 2006, párr.3).

Observación General No. 12 (2009). Su objetivo general es apoyar a los Estados Parte de la Convención sobre los Derechos del Niño en la aplicación efectiva del artículo 12, que establece el derecho de cada niño de expresar su opinión libremente en todos los asuntos que lo afectan, como cuando está expuesto a la violencia intrafamiliar, y el subsiguiente derecho de que esas opiniones se tengan debidamente en cuenta, en función de su edad y madurez (Oficina del Alto Comisionado de Naciones Unidas para los Derechos Humanos, 2009).

Observación General No. 13 (2011). En ella, el Comité explica que se publica este documento debido a la alarmante magnitud e intensidad de la violencia ejercida contra los niños. Por lo tanto, es preciso reforzar y ampliar masivamente las medidas destinadas a acabar con la violencia, para poner fin de manera efectiva a las prácticas, que dificultan el desarrollo de los niños y la posible adopción por las sociedades de medios pacíficos de solución de $\operatorname{conflictos}^{27}$ (Organización de las Naciones Unidas para los Derechos Humanos, 2011). Esta Observación General aborda el análisis jurídico del artículo 19 de la Convención sobre los Derechos del Niño ${ }^{28}$, por considerar que es "la disposición básica en torno a la cual deben girar los debates y estrategias encaminados a combatir y eliminar todas las formas de violencia, en el contexto más amplio de la Convención"(Comité de los Derechos del Niño. CRC/C/GC/13. Observación General No. 13, párr.2 y 7).

El Comité insiste en que siempre ha mantenido la posición de que toda forma de violencia contra los niños es inaceptable, por leve que sea. La frecuencia, la gravedad del daño y la intención de causar daño no son requisitos previos de las definiciones de violencia. Los Estados Parte pueden referirse a estos factores en sus estrategias de intervención para

$26 \mathrm{Al}$ respecto cabe destacar la publicación del Consejo de Europa (2008) Abolición del castigo físico infligido a niños y niñas. Preguntas y respuestas, que promueve un Continente europeo libre de castigo físico a los niños y subraya los efectos positivos de la crianza positiva.

27 En atención al Estudio del Secretario General de las Naciones Unidas sobre la Violencia contra los Niños, en el año 2009 el Comité de Ministros del Consejo de Europa adoptó la Recomendación CM (Rec 2009) 10, que exhorta a los gobiernos de los Estados Miembros a adoptar las medidas establecidas en las Directrices de la política del Consejo de Europa sobre estrategias nacionales para la protección de los niños contra la violencia, tal como figuran en el anexo I de dicho texto. El deseo del Consejo de Europa es que este documento, y el proceso que ha llevado a su adopción, inspire el desarrollo de estrategias nacionales, tanto dentro como fuera de Europa.

$28 \mathrm{El}$ cual se transcribe en la nota 75 de este escrito, junto con otros artículos de la Convención sobre los Derechos del Niño. 
dar respuestas proporcionales que tengan en cuenta el interés superior del niño, pero las definiciones no deben en modo alguno menoscabar el derecho absoluto del niño a la dignidad humana y la integridad física y psicológica, calificando algunos tipos de violencia de legal y/o socialmente aceptables (Comité de los Derechos del Niño. CRC/C/ GC/13. Observación General No. 13, párr.17).

Observación General No. 14 (2013). Su finalidad es mejorar la comprensión y observancia del derecho del niño, a que su interés superior, concepto dinámico en constante evolución ${ }^{29}$, sea evaluado y constituya una consideración primordial o, en algunos casos, la consideración primordial. Esto repercute en la elaboración de todas las medidas de aplicación adoptadas por los gobiernos, las decisiones tomadas por autoridades judiciales y administrativas y entidades públicas o privadas y las directrices relacionadas con las medidas tomadas por personas que se ocupan de los niños, en especial los padres y los cuidadores (Organización de las Naciones Unidas para los Derechos Humanos, 2013). Este documento proporciona un marco para evaluar y determinar el interés superior del niño, cuya plena aplicación exige adoptar un enfoque basado en los derechos, en el que colaboren todos los intervinientes, a fin de garantizar la integridad física, psicológica, moral y espiritual holísticas del niño y promover su dignidad humana.

Observación General No. 15 (2013). Se fundamenta en la importancia de que los niños tienen derecho a oportunidades de supervivencia, crecimiento y desarrollo, en un contexto de bienestar físico, emocional y social, al máximo de sus posibilidades ${ }^{30}$. El Comité reconoce que:

Para la realización del derecho del niño a la salud, deben tenerse en cuenta varios determinantes, algunos de orden individual como la edad, el sexo, el rendimiento escolar, la condición socioeconómica y el domicilio; otros que operan en el entorno inmediato formado por las familias, los compañeros, los maestros y los proveedores de servicios, en particular con respecto a la violencia que pone en peligro la vida y la supervivencia del niño en su entorno inmediato; y determinantes estructurales como políticas, estructuras y sistemas administrativos, valores sociales y culturales y normas. (Naciones Unidos para los Derechos Humanos, 2013, párr.17).

\subsubsection{Observación general No. 20 del Comité de los Derechos Humanos} (1992). El Comité de los Derechos Humanos, encargado de supervisar la implementación del Pacto Internacional de Derechos Civiles y Políticos

29 El Comité subraya en este texto que el interés superior del niño es un concepto triple: es un derecho sustantivo, un principio jurídico interpretativo y una norma de procedimiento.

30En el Preámbulo la Constitución de la Organización Mundial de la Salud (OMS), aprobada por la Conferencia Sanitaria Internacional, Nueva York, julio 22 de 1946, los Estados acordaron entender la salud como estado de completo bienestar físico, mental y social, y no solamente como ausencia de afecciones o enfermedades. Este concepto positivo de salud sienta las bases de la presente observación general en el ámbito de la salud pública. 
declara, en la Observación general No. 20 (Órganos de las Naciones Unidas, 1992), respecto del Artículo 7 del Pacto, referente a la prohibición de la tortura, tratamiento cruel o castigo, adoptada en 1992, en el artículo 7 del Convenio ("Nadie debe ser sometido a torturas o a un tratamiento cruel, inhumano y degradante o castigo"):

la prohibición en el artículo 7 se relaciona no sólo con los actos que causan dolor físico sino también con los actos que causan sufrimiento mental a sus víctimas. Desde la perspectiva del Comité, la prohibición debe extenderse al castigo corporal, que debe incluir la corrección excesiva, empleada como una medida educativa y disciplinaria. Resulta apropiado enfatizar con relación a esto último, que el artículo 7 protege, en particular, a los niños, estudiantes y pacientes en instituciones escolares y de la salud.

2.1.3.3. Observación general No. 13 del Comité de los Derechos Económicos, Sociales y Culturales ${ }^{31}$ (1999). La Observación general No. 13 (1999), acerca del Derecho a la educación (artículo 13 del Pacto), expresa:

desde la perspectiva del Comité, el Castigo Corporal es inconsistente con los principios fundamentales que guían la ley de los Derechos Humanos internacionales - preservados en los Preámbulos de la Declaración Universal de los Derechos Humanos y en los dos Convenios - y la dignidad del individuo. (Red Internacional para los Derechos Económicos, Sociales y Culturales, 1999).

2.1.4. Recomendaciones del Comité para la Eliminación de la Discriminación contra la Mujer. El Comité para la Eliminación de la Discriminación contra la Mujer ha emitido las Recomendaciones generales No. 12 y 19, relacionadas con la violencia contra la mujer en la vida cotidiana, incluida la que ocurre en el hogar. Además, se debe tener en cuenta la Recomendación general No.31, expedida conjuntamente con la Observación General No. 18 del Comité de los Derechos del Niño, en torno a las prácticas nocivas.

2.1.4.1. Recomendación general No. 12 del Comité para la Eliminación de la Discriminación contra la Mujer (1989). Violencia contra la Mujer. El Comité exhorta a los Estados Parte a incluir en sus informes periódicos datos acerca de la legislación vigente para proteger a la mujer de la frecuencia de cualquier tipo de violencia en la vida cotidiana (la violencia sexual, malos tratos en el ámbito familiar, acoso sexual en el lugar de trabajo, etc.). Además, otras medidas adoptadas para erradicar esa violencia, servicios de apoyo a las mujeres que sufren agresiones o malos tratos y estadísticas acerca de la frecuencia de cualquier tipo de violencia contra la mujer y sobre las mujeres víctimas de la violencia.

31 Este órgano se encarga de monitorear la implementación del Pacto Internacional de Derechos Económicos, Sociales y Culturales. 
2.1.4.2. Recomendación general No. 19 del Comité para la Eliminación de la Discriminación contra la Mujer (1992). Violencia contra la Mujer. Como complemento de la Recomendación general No. 12 (1989), acerca del mismo tema, el Comité exhorta a los Estados a adoptar todas las medidas jurídicas y de otra índole para proteger eficazmente a las mujeres contra la violencia ${ }^{32}$. Es fundamental que, en sus informes, los Estados Parte individualicen la violencia contra la mujer y el tipo de violencia que engendra la índole y el alcance de las actitudes, costumbres y prácticas que perpetúan, para cuya superación deben adoptar medidas eficaces ${ }^{33}$.

2.1.4.3. Recomendación general No. 31 del Comité para la Eliminación de la Discriminación contra la Mujer y observación general No. 18 del Comité de los Derechos del Niño (2014). En la Recomendación general No. 31 del Comité para la Eliminación de la Discriminación contra la Mujer y observación general No. 18 del Comité de los Derechos del $\mathrm{Niño}^{34}$ sobre las prácticas nocivas (2014), ambos órganos tienen como objetivo aclarar las obligaciones de los Estados Parte en la Convención sobre la Eliminación de Todas las Formas de Discriminación contra la Mujer y en la Convención sobre los Derechos del Niño, por medio de una orientación autorizada sobre medidas legislativas y de políticas y otras que deben adoptarse para garantizar el pleno cumplimiento de sus obligaciones de eliminar las prácticas nocivas. El texto resalta que dichas

prácticas se fundamentan en la discriminación por razón de sexo, género y edad, entre otras cosas, y a menudo se han justificado invocando costumbres y valores socioculturales y religiosos, además de concepciones erróneas relacionadas con algunos grupos desfavorecidos de mujeres y niños. En general, las prácticas nocivas ${ }^{35}$ suelen ir asociadas a graves formas de violencia o son en sí mismas una forma de violencia contra las mujeres y los niños. (párr.7).

2.1.5 Informes. Para este trabajo interesan El Informe de las Naciones Unidas sobre Violencia contra los Niños, Niñas y Adolescentes y los Reportes anuales de la Representante Especial del Secretario General sobre la violencia contra los niños.

2.1.5.1. El Informe de las Naciones Unidas sobre Violencia contra los Niños, Niñas y Adolescentes, octubre 2006. Este Informe, elaborado por

32 Tales como medidas jurídicas eficaces, medidas preventivas y de protección (párr.24, t. i, ii y iii.)

33 Programas de educación y de información que ayuden a suprimir prejuicios que obstaculizan el logro de la igualdad de la mujer (párr.24, f).

34 Ambos textos adoptados de manera conjunta.

35 Entre estas prácticas se incluyen, sin carácter restrictivo, el abandono de las niñas (vinculado al trato y la atención preferentes que se prestan a los niños varones), restricciones dietéticas extremas, incluso durante el embarazo (alimentación forzada, tabúes alimentarios), exámenes de virginidad y prácticas conexas, ataduras, arañazos, marcas con objetos candentes/provocación de marcas tribales, castigo corporal, lapidación, ritos iniciáticos violentos, infanticidio, e incesto (párr.9). 
el experto independiente Paulo Sérgio Pinheiro, por encargo de la ONU, analiza las diferentes formas de violencia que afectan a los niños y niñas de todo el mundo. Respecto a la violencia intrafamiliar hacia los niños, tema de este estudio, destaca que, en las últimas décadas, se ha reconocido y documentado que la violencia ejercida por los padres y otros miembros cercanos de la familia, puede ser física, sexual y psicológica; asimismo, la desatención deliberada es un fenómeno corriente. A veces, la violencia ejercida contra niños muy pequeños dentro de la familia causa daños permanentes e, incluso, la muerte ${ }^{36}$, por lo que es de vital importancia alentar a los padres a que utilicen exclusivamente métodos no violentos de disciplina ${ }^{37}$.

Eliminar y dar respuesta a la violencia contra los niños es, quizá, más difícil en el contexto de la familia que en cualquier otro, dado que esta es considerada, generalmente, la más privada de todas las esferas de esta índole. Sin embargo, los derechos de los niños a la vida, la supervivencia, el desarrollo, la dignidad y la integridad física no terminan en la puerta del hogar familiar, ni tampoco acaban ahí las obligaciones que tienen los Estados de garantizar tales derechos a los niños ${ }^{38}$. Por esto, el Estudio, además de llamar a la actuación urgente de la comunidad internacional para prevenir y responder a esta problemática, presenta recomendaciones para guiar el proceso de seguimiento y solicita el nombramiento de un Representante Especial del Secretario General sobre la Violencia contra los Niños, para favorecer su difusión e implementación ${ }^{39}$.

\subsubsection{Informes anuales de la Representante Especial del Secretario} General sobre la violencia contra los niños. La Representante Especial del Secretario General ofrece un informe anual al Consejo de Derechos Humanos y a la Asamblea General acerca del progreso en la prevención y respuesta a la violencia (Representante Especial del Secretario General de las Naciones Unidas sobre la violencia contra los niños, 2010 - 2014) ${ }^{40}$. Además de sus informes ordinarios, la Representante Especial del

36 Ibídem, párr.38.

37 Ibídem, párr.42.

38 Ibídem, párr.38.

39 La Asamblea General de Naciones Unidas, mediante la Resolución 62/141 de 2007, pide al Secretario General el nombramiento de dicho Representante para actuar en calidad de promitente defensor mundial e independiente para la promoción y eliminación de toda forma de violencia contra los niños. En atención a esta solicitud, el 1 de mayo de 2009, el Secretario General nombra a la Dra. Marta Santos Pais para ocupar dicho cargo, en que se mantiene hasta el presente. Su mandato ha sido renovado en dos oportunidades; la última, el 5 de febrero de 2016, coincidió con el décimo aniversario del Estudio de las Naciones Unidas sobre la Violencia contra los Niños, el cual ha asesorado e impulsado.

40 Los informes del 2010 al 2014 se pueden leer en el sitio web de la Representante Especial del Secretario General sobre la Violencia contra los Niño: http://srsg.violenceagainstchildren. org/es/category/document-type/srsg-reports. Los informes correspondientes al 2015 y 2016 están publicados en https://documents-dds-ny.un.org/doc/UNDOC/GEN/G16/000/93/ PDF/G1600093.pdf?OpenElement y https://documents-dds-ny.un.org/doc/UNDOC/ GEN/G17/000/57/PDF/G1700057.pdf?OpenElement 
Secretario General puede emitir informes temáticos sobre temas clave de interés ${ }^{41}$ (Oficina de la Representante Especial del Secretario General sobre la Violencia contra los Niños, 2017).

En el último Informe (2016), la Representante resalta:

desde la aprobación de la Convención sobre los Derechos del Niño en 1989, el mundo ha hecho enormes avances hacia la realización de los derechos del niño. Sin embargo, la visión de la Convención no se materializará plenamente a menos que los derechos del niño sean uno de los pilares que sustentan a la sociedad y que son aceptados como un valor fundamental del diálogo entre generaciones. (párr.101).

Más adelante, señala que "la aplicación de la Agenda 2030 para el Desarrollo Sostenible ofrece una oportunidad única para renovar los compromisos y revitalizar las medidas para poner fin a la violencia contra los niños ${ }^{42 "}$ (párr.103).

\subsection{El corpus juris interamericano}

El corpus juris interamericano se relaciona con los derechos del niño y su protección frente a la violencia intrafamiliar Está compuesto por

41 De especial interés para este trabajo es la Encuesta mundial Hacia un Mundo sin Violencia, publicada en el año 2013. El texto analiza los avances en relación con la prevención y la erradicación de la violencia contra los niños, a partir de la publicación del Informe de Naciones Unidas sobre la Violencia contra los Niños en el año 2006 y destaca que, si bien se ha avanzado desde el citado Informe de 2006, el progreso ha sido lento, desigual y fragmentado y ha impedido disminuir de forma significativa la violencia contra la niñez. Por tal motivo, recomienda que los Estados perseveren en su esfuerzo en pro de la solución de esta problemática. Se puede consultar en http://srsg.violenceagainstchildren.org/ sites/default/files/global_survey/spanish/SPANISH_Toward\%20a\%20World\%20Free\%20 from\%20Violence_06_28_2016_Prf2.pdf.

En el Informe de $201 \overline{6}$, también se alude a la preparación de material adaptado a los niños para que estén informados y empoderados en cuanto a su derecho a no ser víctimas de violencia. También se procedió a la definición de indicadores de calidad sobre la prevalencia de la exposición de los niños a la violencia y su gravedad. Asimismo, se menciona la iniciativa Ya es hora de terminar con la violencia contra los niños, presentada por la Representante Especial, en marzo de 2016, durante el 31 período ordinario de sesiones del Consejo de Derechos Humanos.

42 En igual sentido, el Informe del Alto Comisionado de las Naciones Unidas para los Derechos Humanos (2016), Protección de los derechos del niño en el marco de la aplicación de la Agenda 2030 para el Desarrollo Sostenible destaca que "el cumplimiento de todas las metas del Objetivo de Desarrollo Sostenible 16, relativas a la protección contra la violencia y a otras libertades fundamentales, debe ser prioritario para todos los países durante la aplicación de la Agenda 2030, junto con las metas relacionadas previstas en relación con el Objetivo 5, sobre la igualdad de género. Los Estados deben respetar los compromisos contraídos en la Agenda 2030". Disponible en: https://documents-dds-ny.un.org/doc/UNDOC/GEN/ G16/433/96/PDF/G1643396.pdf?OpenElement 
convenios, protocolos, jurisprudencia ${ }^{43}$, opiniones consultivas de la Corte Interamericana de Derechos Humanos, trabajos, informes de casos, informes temáticos de la Comisión Interamericana de Derechos Humanos y guías para la aplicación de la Convención de Belém do Pará del Mecanismo de Seguimiento de dicho texto, MESECVI.

2.2.1. La normativa jurídica regional. La normativa jurídica de alcance regional, aplicable en Colombia, comprende la Declaración Americana sobre Derechos y Deberes del Hombre de $1948^{44}$, la Convención Americana sobre Derechos Humanos o Pacto de San José de Costa Rica de 1969 (Departamento de Derecho Internacional - Organización de los Estados Americanos OEA, 1969) ${ }^{45}$, el Protocolo Adicional a la Convención Americana sobre Derechos Humanos en materia de Derechos Económicos, Sociales y Culturales (Protocolo de San Salvador) (Departamento de Derecho Internacional - Organización de los Estados Americanos OEA, 1988), y la Convención Interamericana ${ }^{46}$ para prevenir, sancionar y erradicar la violencia contra la Mujer (Departamento de Derecho Internacional - Organización de los Estados Americanos OEA,

43 La Corte Interamericana de Derechos Humanos publica cuadernillos con el fin de dar a conocer su jurisprudencia en diversos temas de relevancia e interés regional, tales como el No. 4 Género y Derechos Humanos de las Mujeres y el No. 7 Control de Convencionalidad, ambos del 2015, los cuales permiten profundizar en algunos de los temas tratados en este escrito.

44 En el Preámbulo expresa que "todos los hombres nacen libres e iguales en dignidad y derechos y, dotados como están por naturaleza de razón y conciencia, deben conducirse fraternalmente los unos con los otros". En el artículo 7, se establece que "toda mujer en estado de gravidez o en época de lactancia, así como todo niño, tienen derecho a protección, cuidados y ayuda especiales". Disponible en: http://www.cidh.org/basicos/Basicos1.htm.

45 En el capítulo I, correspondiente a la enumeración de los deberes de los Estados, el artículo 1.1. dispone que "los Estados Parte en esta Convención se comprometen a respetar los derechos y libertades reconocidos en ella y a garantizar su libre y pleno ejercicio a toda persona que está sujeta a su jurisdicción [...]". El artículo 5 dispone que "[...] nadie debe ser sometido a torturas ni a penas o tratos crueles, inhumanos o degradantes [...]". Asimismo, el artículo 19. Derecho del niño señala que "todo niño tiene derecho a las medidas de protección que su condición de menor requieren por parte de su familia, de la sociedad y del Estado".

46 En el marco del Consejo de Europa, vigente desde el año 2014, el Convenio sobre la prevención y lucha contra las mujeres y la violencia doméstica. 
1994) ${ }^{47}$, suscrita en Belém do Pará.

\subsubsection{Aportes de los órganos del Sistema Interamericano de Derechos Humanos. En cuanto al sistema interamericano de protección de los derechos humanos, para efectos de este escrito, son relevantes los}

47En el preámbulo se expresa que "la violencia contra la mujer constituye una violación de los derechos humanos y las libertades fundamentales y limita total o parcialmente a la mujer el reconocimiento, goce y ejercicio de tales derechos y libertades. [...] La violencia contra la mujer es una ofensa a la dignidad humana y una manifestación de las relaciones de poder históricamente desiguales entre mujeres y hombres [...]. Convencidos de que la eliminación de la violencia contra la mujer es condición indispensable para su desarrollo individual y social y su plena e igualitaria participación en todas las esferas de vida [...]" De acuerdo con el artículo 1, "debe entenderse por violencia contra mujer cualquier acción o conducta, basada en su género, que cause muerte, daño o sufrimiento físico, sexual o psicológico a la mujer, tanto en el ámbito público como en el privado". Asimismo, el artículo $2^{\circ}$ expresa que "se entenderá que violencia contra la mujer incluye la violencia física, sexual y psicológica: a) que tenga lugar dentro de la familia [...]". El artículo $3^{\circ}$. declara que "toda mujer tiene derecho a una vida libre de violencia tanto en el ámbito público como en el privado". En cuanto a los deberes de los Estados, en el artículo $7^{\circ}$ se expresa que "los Estados Parte condenan todas las formas de violencia contra la mujer y convienen en adoptar, por todos los medios apropiados y sin dilaciones, políticas, orientadas a prevenir, sancionar y erradicar dicha violencia y e llevar a cabo lo siguiente: [...] c)incluir en su legislación interna normas penales, civiles y administrativas, así como las de otra naturaleza que sean necesarias para prevenir, sancionar y erradicar la violencia contra la mujer y adoptar las medidas administrativas apropiadas que sean del caso [...]". Con base en el artículo 80. "los Estados Parte convienen en adoptar, en forma progresiva, medidas específicas, inclusive programas para: a) Fomentar el conocimiento y la observancia del derecho de la mujer a una vida libre de violencia, y el derecho de la mujer a que se respeten y protejan sus derechos humanos; b) Modificar los patrones socioculturales de hombres y mujeres, incluyendo el diseño de programas de educación formales y no formales apropiados a todo nivel del proceso educativo, para contrarrestar prejuicios y costumbres y todo otro tipo de prácticas que se basen en la premisa de la inferioridad o superioridad de cualquiera de los géneros o en los papeles estereotipados para el hombre y la mujer que legitimizan o exacerban la violencia contra la mujer; [...] e) Fomentar y apoyar programas de educación gubernamentales y del sector privado destinados a concientizar al público sobre los problemas relacionados con la violencia contra la mujer, los recursos legales y la reparación que corresponda [...]". El artículo $9^{\circ}$ expresa que "para la adopción de las medidas a que se refiere este capítulo, los Estados Parte tendrán especialmente en cuenta la situación de vulnerabilidad a la violencia que pueda sufrir la mujer en razón, entre otras, de su raza o de su condición étnica de migrante, refugiada o desplazada. En igual sentido se considerará a la mujer que es objeto de violencia cuando es menor de edad [...]". En el capítulo IV, el artículo 10 dispone que "con el propósito de proteger el derecho de la mujer a una vida libre de violencia, en los informes nacionales a la Comisión Interamericana de Mujeres, los Estados Parte deberán incluir información sobre las medidas adoptadas para prevenir y erradicar la violencia contra la mujer, para asistir a la mujer afectada por la violencia, así como sobre las dificultades que observen en la aplicación de las mismas y los factores que contribuyan a la violencia contra la mujer". 
siguientes: la Opinión Consultiva ${ }^{48}$ OC-17/02 Condición Jurídica y Derechos Humanos del Niño (Corte Interamericana de Derechos Humanos, 2002), el libro La infancia y sus derechos en el sistema interamericano de protección de derechos humanos (2008), el Informe No. 54/01 Caso 12-051, Maria Da Penha Maia Fernandez, de abril 16 de 2001 (ambos de la Comisión Interamericana de Derechos Humanos), además de sus informes temáticos ${ }^{49}$ sobre $e l$ Castigo Corporal y los Derechos Humanos de las Niñas, Niños y Adolescentes de agosto 5 de 2009; los Estándares jurídicos vinculados a la igualdad de género $y$ a los derechos de las mujeres en el sistema interamericano de derechos humanos. Desarrollo y aplicación (2011) y la Universalización del sistema interamericano de derechos humanos. Consideraciones sobre la ratificación universal de la Convención Americana yotros tratados interamericanos en materia de derechos humanos (2014). También son relevantes las guías para la aplicación de la Convención de Belém do Pará y la correspondiente al sistema de indicadores de progreso para la medición de la implementación de este documento, publicadas por el MESECVI.

\subsubsection{La opinión consultiva OC-17/02 sobre la Condición Jurídica} y Derechos Humanos del Niño de la Corte Interamericana de Derechos Humanos (2002). En la opinión consultiva OC-17/02 sobre la Condición Jurídica y Derechos Humanos del Niño (2002), la Corte Interamericana de Derechos Humanos sostiene que los Estados Parte en la Convención Americana de Derechos Humanos "tienen el deber [...] de tomar todas las medidas positivas que aseguren protección a los niños contra malos tratos, sea en sus relaciones con las autoridades públicas, sea en las relaciones interindividuales o con entes no estatales". La Corte cita disposiciones de la Convención sobre los Derechos del Niño, conclusiones del Comité de los Derechos del Niño y también fallos del Tribunal Europeo de Derechos Humanos, en relación con las obligaciones de los Estados de proteger a los niños contra la violencia, incluso en la familia. Para concluir, expresa que "el Estado tiene el deber de adoptar todas las medidas positivas para asegurar la plena vigencia de los derechos del niño".

\footnotetext{
48 Son pronunciamientos de ciertos órganos internacionales, a los que se les ha atribuido una competencia consultiva, como la Corte Internacional de Justicia y la Corte Interamericana de Derechos Humanos. Responden a una consulta elevada en relación con el alcance de las disposiciones de los tratados cuyo cumplimiento debe ser verificado por dichas cortes. Si bien no son obligatorias, tienen un relevante valor doctrinal, pues expresan la interpretación autorizada del respectivo tratado. En esa medida, según el artículo 93 de la Constitución Política de Colombia de 1991, tales opiniones son relevantes para definir el alcance de los derechos que integran el bloque de constitucionalidad (Botero y Guzmán, 2007, p.130).

49 En el Sistema Internacional de Protección de los Derechos Humanos, algunos órganos elaboran y publican informes temáticos en los que realizan un diagnóstico sobre la situación de los derechos humanos, en particular en alguna región o Estado, o se refieren a la situación de un derecho humano, en particular en varios Estados, como los de la Relatoría de la Comisión Interamericana de Derechos Humanos. También los expertos independientes designados por las organizaciones internacionales elaboran informes, v. gr. el Informe del experto independiente para el estudio de la violencia contra los niños, de las Naciones Unidas, Paulo Sérgio Pinheiro, incluido en este estudio.
} 


\subsubsection{Contribuciones de la Comisión Interamericana de Derechos Humanos}

La infancia y sus derechos en el sistema interamericano de protección de derechos humanos (2008).

Este libro desarrolla, desde una perspectiva general, el estado a la fecha de las normas, mecanismos y decisiones interamericanas en materia de derechos del niño. La publicación destaca que:

El Sistema Interamericano coexiste con otros Sistemas Internacionales de Derechos Humanos como son el Sistema Universal; así como, los sistemas regionales que existen en Europa y África. Ello implica que los diferentes sistemas de protección de derechos humanos se nutren y se complementan mutuamente en lo que concierne al desarrollo de estándares internacionales de derechos humanos ${ }^{50}$. (párr.52).

También incluye de manera expresa la noción sobre el corpus juris de los derechos humanos del niño, lo cual significa el reconocimiento a la existencia de un conjunto de normas fundamentales que se encuentran vinculadas con el fin de garantizar los derechos humanos de los niños ${ }^{51}$.

\section{Informe No. 54/01 Caso 12-051 Maria da Penha Maia Fernandez.}

En este informe, la Comisión Interamericana de Derechos Humanos concluye que el Estado brasileño violó, en perjuicio de la señora Maria da Penha Maia Fernandes, los derechos a las garantías judiciales y a la protección judicial, garantizados por los artículos 8 y 25 de la Convención Americana, en concordancia con la obligación general de respetar y garantizar los derechos, prevista en el artículo 1 (1) de dicho instrumento, en los artículos II y XVII de la Declaración y en el artículo 7 de la Convención de Belém do Pará. Concluye también que esta violación ocurre como parte de un patrón discriminatorio respecto a la tolerancia de la violencia doméstica contra las mujeres en Brasil, por ineficacia de la acción judicial.

50 El texto señala que "esta relación fortalece la defensa y la promoción de los derechos humanos de los niños, las niñas y los adolescentes. Un ejemplo concreto de cómo el Comité de Derechos del Niño utiliza las decisiones del sistema interamericano se encuentra en la Observación General $N^{\circ} 8$ sobre la protección del niño contra el castigo corporal y otras formas de trato cruel, inhumano o degradante, en la cual el Comité cita la jurisprudencia de la Corte Interamericana para establecer el alcance de la obligación de adoptar medidas positivas por parte del Estado para garantizar los derechos del niño, la niña y el adolescente" (párr.54).

51 La jurisprudencia de la Corte Interamericana ha reconocido la existencia de un corpus juris sobre derechos humanos de los niños, al señalar que "tanto la Convención Americana como la Convención sobre los Derechos del Niño forman parte de un muy comprensivo corpus juris internacional de protección de los niños que debe servir a esta Corte para fijar el contenido y los alcances de la disposición general definida en el artículo 19 de la Convención Americana" (Corte I.D.H., Condición Jurídica y Derechos Humanos del Niño. Opinión Consultiva OC-17/02 de 28 de agosto de 2002. Serie A No. 17, párr.37, 53 y Caso de los "Niños de la Calle" (Villagrán Morales y otros). Sentencia de 19 de noviembre de 1999. Serie C No. 63, párr. 194). 
La Comisión recomienda al Estado llevar a cabo una investigación seria, imparcial y exhaustiva para determinar la responsabilidad penal del autor del delito de tentativa de homicidio en perjuicio de la señora Fernandes y para determinar si hay otros hechos o acciones de agentes estatales que hayan impedido el procesamiento rápido y efectivo del responsable. Recomienda también la reparación efectiva y pronta de la víctima, así como la adopción de medidas en el ámbito nacional para eliminar esta tolerancia estatal frente a la violencia doméstica contra mujeres. Este es el primer caso de aplicación de la Convención de Belém do Pará. (Comisión Interamericana de Derechos Humanos, 2001).

\section{Informes temáticos de la Comisión Interamericana de Derechos Humanos}

Informe sobre el castigo corporal y los derechos humanos de las niñas, niños y adolescentes - Relatoría sobre los derechos de la niñez (2009)

Este informe es elaborado por la Relatoría sobre los Derechos de la Niñez y tiene como marco conceptual los retos y avances tras 20 años de la adopción de la Convención sobre los Derechos del Niño. Su objetivo es recomendar a los Estados del hemisferio americano acciones concretas para avanzar integralmente en la protección de los derechos humanos de los niños, con base en la gravedad y seriedad del castigo corporal en la región. La CIDH observa que la utilización de esta práctica, además de ser contraria al respeto de los derechos humanos, expresa una concepción del niño como objeto y no como sujeto de derechos, de acuerdo con lo establecido en la Convención sobre los Derechos del Niño, (párr.24). A partir de la doctrina de la protección integral sustentada en dicha Convención, todas las decisiones que, en la familia, la sociedad, o el Estado, afecten a un niño tendrán que tener en cuenta su interés superior $^{52}$, es decir, la vigencia efectiva de la integralidad de sus derechos.

En cuanto a la esfera de protección de los derechos humanos de los niños, en el sistema interamericano de derechos humanos, la Convención Americana sobre Derechos Humanos o Pacto de San José de Costa Rica, en el artículo 19, establece que "todo niño tiene derecho a las

\footnotetext{
52 En esta misma línea, la Corte Interamericana de Derechos Humanos afirma que "[...] la expresión interés superior del niño, consagrada en el artículo 3 de la Convención sobre los Derechos del Niño, implica que el desarrollo de éste y el pleno ejercicio de sus derechos deben ser considerados como criterios rectores para la elaboración de normas y la aplicación de estas en todos los órdenes relativos a la vida del niño. La protección de los niños en los instrumentos internacionales tiene como objetivo último el desarrollo armonioso de la personalidad de aquellos y el disfrute de los derechos que les han sido reconocidos. Corresponde al Estado precisar las medidas que adoptará para atender ese desarrollo en su propio ámbito de competencia y apoyar a la familia en la función que esta naturalmente tiene a su cargo para brindar protección a los niños que forman parte de ella" (Corte I.D.H., Condición Jurídica y Derechos Humanos del Niño. Opinión Consultiva OC-17/02 de 28 de agosto de 2002. Serie A. No. 17, párrafo 53 y 137/6).
} 
medidas de protección que su condición de menor requieren por parte de su familia, de la sociedad y del Estado". Esta protección especial, expresa la $\mathrm{CIDH}$, se funda en:

El reconocimiento de que los Estados deben tomar medidas positivas y preventivas teniendo en cuenta las condiciones especiales del niño; vale decir la vulnerabilidad a la que está expuesto el niño y su dependencia de los adultos para el ejercicio de algunos derechos, el grado de madurez, su desarrollo progresivo y el desconocimiento de sus derechos humanos y de los mecanismos de exigibilidad que no permite ubicarlo en una situación similar a la de los adultos y por tanto justifica la adopción de medidas especiales. (párr.23).

La CIDH considera que la autoridad parental debe ser interpretada en relación con la indivisibilidad e interdependencia de los derechos humanos ${ }^{53}$ para asegurar la protección integral de los derechos del niño ${ }^{54}$. En tal sentido:

la CIDH sostiene que las legislaciones que permiten a los padres utilizar el castigo corporal para corregir en forma "moderada" o "razonable" a sus hijos no se adecuan a los estándares internacionales aplicables a la institución de la patria potestad y por tanto, no garantizan protección adecuada de los niños contra el castigo corporal. (párr.91).

Estándares jurídicos vinculados a la igualdad de género y a los derechos de las mujeres en el sistema interamericano de derechos humanos. Desarrollo y aplicación (2011)

Este Informe analiza sentencias judiciales que aplican de forma explícita instrumentos interamericanos como la Convención Americana y la Convención de Belém do Pará para resolver asuntos relacionados con el presente trabajo, tales como la violencia doméstica, el vínculo entre la discriminación y la violencia, el deber de actuar con la debida diligencia, la violencia y los derechos económicos sociales y culturales de las mujeres y la violencia física y psicológica.

53 La Declaración y el Programa de Acción de Viena, adoptada durante la Conferencia Mundial de Derechos Humanos, el 23 de junio de 1993 establece que "Todos los derechos humanos son universales, indivisibles e interdependientes y están relacionados entre sí. La comunidad internacional debe tratar los derechos humanos en forma global y de manera justa y equitativa, en pie de igualdad y dándoles a todos el mismo peso. Debe tenerse en cuenta las particularidades nacionales y regionales, así como de los diversos patrimonios históricos, culturales y religiosos, pero los Estados tienen el deber, sean cuales fueren sus sistemas políticos, económicos y culturales, de promover, proteger todos los derechos humanos y libertades fundamentales". Disponible en http://www.unhchr.ch/huridocda/ huridoca.nsf/(Symbol)/A.CONF.157.23.Sp.

$54 \mathrm{La}$ CIDH señala, como ejemplo, que si un niño es víctima de castigo corporal no se vulnera el derecho a la integridad personal sino que también se produce la afectación del derecho del niño a una vida digna libre de violencia. 
Universalización del sistema interamericano de derechos humanos. Consideraciones sobre la ratificación universal de la Convención Americana y otros tratados interamericanos en materia de derechos humanos (2014)

Este documento busca fomentar la observancia general de los derechos humanos, promoviendo no solamente la universalidad de la ratificación de los tratados que conforman el sistema interamericano, sino también el cumplimiento de las disposiciones contenidas en dichos instrumentos ${ }^{55}$. Son fundamentales para su realización factores como: la voluntad política, la fortaleza de actuación de la sociedad civil, la capacidad de prevención y respuesta de las instituciones estatales, el conocimiento por el público en general de sus derechos humanos y la creación de condiciones propicias para su ejercicio.

En relación con la temática que se aborda en este escrito, el texto destaca la Convención de Belém de Pará como el instrumento más ratificado del sistema interamericano ${ }^{56}$. Para la Comisión Interamericana esto es reflejo de un consenso regional acerca de la gravedad del problema de la violencia contra las mujeres, la discriminación que la sustenta y la necesidad de adoptar estrategias integrales para su prevención, sanción y erradicación.

Publicaciones del Mecanismo de Seguimiento de la Convención de Belém do Pará. MESECVI

\section{Guía para la aplicación de la Convención de Belém do Pará. MESECVI (2014).}

En la introducción de la guía, se señala que:

aunque se ha avanzado considerablemente en toda la región en promover la interpretación de la violencia contra la mujer como una violación de los derechos humanos, las actitudes patriarcales y los estereotipos profundamente arraigados con respecto a las funciones y responsabilidades de las mujeres y los hombres en la familia y la sociedad siguen reforzando la desigualdad. La persistencia de estereotipos suele profundizar las normas sociales que subordinan a las mujeres, y sigue constituyendo el obstáculo principal para hacer efectivo el respeto de los derechos humanos de las mujeres.

Esta situación conlleva a que el MESECVI impulse iniciativas como este texto en aras de apoyar a los Estados en su obligación de proteger los derechos humanos de las mujeres y eliminar las situaciones de violencia que puedan afectarlas, lo cual redunda en el bienestar del núcleo familiar.

55 El Informe resalta que la aplicación de los estándares del sistema interamericano de derechos humanos en el continente americano es un proceso heterogéneo y lento, lo cual exige esfuerzos concretos de los Estados para superar este escollo.

56 A la fecha, los Estados que no la han ratificado son Estados Unidos, Canadá y Cuba. 
Guía práctica para la aplicación del sistema de indicadores de progreso para la medición de la implementación de la Convención de Belém do Pará. MESECVI (2015).

El objetivo de esta guía es promover la consolidación del sistema de indicadores de progreso para la medición de la implementación de la Convención de Belém do Pará en el ámbito regional. Asimismo, persigue facilitar su utilización y promueve procesos de integración intersectorial e interinstitucional en el abordaje de la violencia contra las mujeres, con el fin de impulsar respuestas que involucren de manera coordinada a las distintas instancias públicas y sociales.

\section{LA ADECUACIÓN DE LAS NORMAS JURÍDICAS INTERNAS A LOS INSTRUMENTOS JURÍDICOS DEL SISTEMA INTERAMERICANO Y A LOS PATRONES INTERPRETATIVOS DE LA CORTE INTERAMERICANA DE DERECHOS HUMANOS}

Como se ha expresado en este escrito, el desarrollo del derecho internacional de los derechos humanos ha dado lugar a la conceptualización de un corpus juris, evidencia de la importancia de los instrumentos internacionales en dicho ámbito frente al derecho interno. Esto apareja la necesidad de articular ambas fuentes mediante su retroalimentación y complementariedad, para afianzar el sistema de derechos y garantías (Bazán, V., 2017), lo cual ha traído como consecuencia la aparición de una institución que actualmente es una herramienta eficaz para la aplicación del Derecho Internacional de los Derechos Humanos en el ámbito interno: el control de convencionalidad, que se ejerce en el sistema interamericano ${ }^{57}$, abarcado en este estudio, y al que se hará referencia a continuación.

El control de convencionalidad en el sistema interamericano de protección de los derechos humanos

El desarrollo jurisprudencial de la figura del control de convencionalidad permite distinguir dos modalidades, una tiene lugar en el ámbito internacional y la otra en el ámbito interno.

En el plano internacional, es la Corte Interamericana de Derechos Humanos la encargada de juzgar en casos concretos, mediante el denominado control concentrado, si un acto, una normativa de derecho interno y la jurisprudencia de los jueces domésticos resultan incompatibles con los instrumentos internacionales del sistema interamericano y/o con

57 Importa tener presente que este control de convencionalidad también lo ejercitan la Corte Europea de Derechos Humanos respecto de los Estados parte de la Convención Europea de Derechos Humanos y la Corte de Luxemburgo respecto de los Estados miembros de la Unión Europea, entre otros sistemas. 
sus patrones interpretativos ${ }^{58}$. También procede cuando el Estado ha incumplido el deber de adecuar su ordenamiento jurídico para garantizar efectivamente el ejercicio de los derechos humanos reconocidos en los instrumentos jurídicos del sistema interamericano de protección de los derechos humanos.

En el contexto interno, el llamado control difuso es aquel a cargo de los jueces nacionales ${ }^{59}$ que desarrollan de manera oficiosa, es decir, aun cuando las partes no lo hubiesen planteado. Se hace extensivo a las demás autoridades públicas ${ }^{60}$ y consiste en la evaluación de las actuaciones de los diversos órganos del poder público y su conformidad con las obligaciones internacionales del Estado en la esfera interamericana. De ahí, se sigue que el control de convencionalidad es una exigencia del principio consuetudinario de derecho internacional, según el cual el derecho interno no es excusa para el incumplimiento de los acuerdos internacionales y, además, es expresión de los principios de buena fe y pacta sunt servanda ${ }^{61}$.

A continuación, se presentan ejemplos de sentencias de diferentes Cortes del continente americano en las que se aplican de forma explícita instrumentos interamericanos, como la Convención Americana sobre Derechos Humanos y la Convención de Belém do Pará, para resolver asuntos relacionados con la violencia intrafamiliar.

Actos de violencia inminentes. Expediente No. 31.258 "B., M.P. c/G., R.A. s/protección contra la violencia intrafamiliar", Tribunal de Familia No. 3, Departamento Judicial de Lomas de Zamora (20 de julio de 2006), Argentina

El Tribunal de Familia aborda el problema de la violencia doméstica y lo caracteriza como una forma de violencia contra las mujeres, como un

58 La Corte Interamericana de Derechos Humanos ha desarrollado interpretaciones normativas a modo de estándares interamericanos que proponen un marco hermenéutico de los instrumentos jurídicos del sistema interamericano. Por consiguiente, los tribunales nacionales deben analizar si la pauta interpretativa del órgano internacional puede ser aplicado.

59 Corte IDH, "Caso Almonacid Arellano y otros vs. Chile", Sentencia de Excepciones Preliminares, Fondo, Reparaciones y Costas, 26 de septiembre de 2006, Serie C, No. 154, párrafo 124. Corte IDH, "Caso Trabajadores Cesados del Congreso ('Aguado Alfaro y otros') vs. Perú, Sentencia de Excepciones Preliminares, Fondo, Reparaciones y Costas, 24 de septiembre de 2006, Serie C, No. 158, párrafo 128.

60 Corte IDH, "Caso Cabrera García y Montiel Flores vs. México", Sentencia de Excepción Preliminar, Fondo, Reparaciones y Costas, 26 de noviembre de 2010, Serie C, No. 220, párrafo 225.

Corte IDH "Caso Gelman vs. Uruguay". Sentencia de Fondo y Reparaciones, 24 de febrero de 2011, Serie C, No. 221, párrafo 239.

Corte IDH, Caso López Mendoza vs. Venezuela", Sentencia de Fondo, Reparaciones y Costas, 1 de septiembre de 2011, Serie C, No. 223, párrafo 228.

Corte IDH, "Caso Atala Riffo y Niñas vs. Chile", Sentencia de Fondo, Reparaciones y Costas, 24 de febrero de 2012, Serie C, No. 239, párrafo 284.

61 Convención de Viena sobre el Derecho de los Tratados de 1969, arts. 26 y 27. 
problema de derechos humanos y como un fenómeno social, que debe interpretarse en el marco del sistema de protección de los derechos humanos internacional e interamericano. Esto conlleva el examen de las consecuencias del incumplimiento de los compromisos internacionales por parte de los Estados en los casos en que las políticas, la legislación y la jurisprudencia no se adecuen efectivamente a dicha normativa. En este análisis, hace referencia al caso de Maria da Penha Maia Fernandez vs. Brasil y al informe de la CIDH sobre La Situación de los Derechos de la Mujer en Ciudad Juárez, México: El Derecho a No ser Objeto de Violencia y Discriminación.

Debida diligencia: Causa No. 13.240 - "Calle Aliaga, Marcelo s/Recurso de casación"- Cámara 11, Sala de Casación Penal-30/11/2010, Argentina

En esta sentencia la Cámara plantea consideraciones jurídicas relacionadas con el deber de actuar con la debida diligencia requerida para investigar y sancionar la violencia contra las mujeres bajo la Convención de Belém do Pará (art. 7b).

Violencia doméstica: Supremo Tribunal Federal, 24 de marzo de 2011. Constitucionalidad del artículo 41 de la Ley de Maria da Penha, Brasil

En esta sentencia, el Pleno del Supremo Tribunal Federal confirmó por unanimidad la constitucionalidad del artículo 41 de la Ley 11.340/2006 (Ley Maria da Penha), artículo que impide beneficios determinados para los agresores, como la suspensión del proceso penal, entre otros. En la sentencia, se afirma que los crímenes que tienen lugar en el ámbito doméstico contra la mujer son de extrema gravedad, repercuten en todos los integrantes de su familia (incluyendo los niños), generan violencia en el futuro y, por ello, deben ser combatidos. Estos argumentos están sustentados en los objetivos, el texto y en el contenido de la citada Ley.

Impacto de la violencia intrafamiliar. RIT-F 980-2010, RUC 10-20361810-2, Tribunal de Familia, 25 de noviembre de 2010, Chile

El Tribunal condena al agresor por violencia intrafamiliar y presenta consideraciones acerca del impacto de este fenómeno en la víctima y su familia. Para su fallo, toma en consideración la Convención Interamericana para prevenir, sancionar y erradicar la violencia contra la mujer y cita a la Convención sobre la eliminación de todas las formas de discriminación contra la mujer.

Violencia física, psicológica y económica contra la mujer. Corte Constitucional. Sentencia T-021/16. M.P. Luis Ernesto Vargas Silva. Colombia

En este fallo, la Corte Constitucional, al referirse a los estatutos jurídicos internacionales de protección de los derechos de las mujeres, expresa:

en el marco del Sistema Interamericano de Derechos Humanos, tanto la Comisión Interamericana de Derechos Humanos como la Corte 
Interamericana han emitido una serie de pronunciamientos y decisiones de las cuales es posible extraer estándares normativos aplicables a casos concretos, al igual que un mínimo de obligaciones para los Estados Parte de la Convención ${ }^{62}$. Gran parte de este desarrollo se ha dado a partir de la adopción de la Convención de Belém do Pará (1994), y la influencia que el Sistema Universal tuvo sobre las decisiones regionales.

Más adelante señala: "los estándares internacionales constituyen fuentes de obligación del Estado, pero también son normas aplicables a casos concretos". (Departamento de Derecho Internacional - Organización de los Estados Americanos OEA, 1994)

Violencia de género y violencia intrafamiliar. Corte Suprema de Justicia. Sala de Casación Civil. STC17090-2016. M. P. Luis Armando Tolosa Villabona. Colombia.

En las consideraciones, la Sala precisa que:

Como se señaló, no podía dictar una decisión meramente formal sin una perspectiva de género, pues los jueces, al igual que todas las autoridades públicas, están llamados no sólo a seguir lo dispuesto en la Constitución Política y en las normas, sino además, a efectuar un control de convencionalidad, el cual les impone, indefectiblemente, revisar la Convención Americana sobre Derechos Humanos y los tratados concordantes, tales como la Convención Interamericana para prevenir, sancionar y erradicar la violencia contra la mujer -"Convención De Belém Do Pará”-, ratificada por Colombia desde el 10 de marzo de 1996.

Más adelante expresa:

De igual modo, para efectos de garantizar prerrogativas de orden fundamental, en este asunto, también resulta viable acudir a otros instrumentos internacionales como la Convención sobre la Eliminación de Todas las Formas de Discriminación contra la Mujer -Cedaw- adoptada por la Asamblea General de las Naciones Unidas el 18 de diciembre de 1979 y aprobada por Colombia mediante la Ley 51 de 1981; así como a “(..) los estándares jurídicos vinculados a la igualdad de género y a los derechos de las mujeres en el sistema interamericano de derechos humanos (...)", definidos por la CIDH en el informe de 3 noviembre 2011".

Violencia de género y violencia intrafamiliar. Corte Suprema de Justicia. Sala de Casación Civil. STC10829-2017. M.P. Luis Armando Tolosa Villabona. Colombia.

En las consideraciones de esta providencia, se expresa que es menester precisar que la violencia ejercida contra la mujer desde cualquier ángulo es 
una práctica desdeñable que merece total reproche. El Estado de Derecho Constitucional no puede tolerar el ejercicio de la violencia física o moral en las relaciones obligatorias, mucho menos la de género, tampoco contra los ancianos, niños o contra cualquier sujeto de derecho sintiente. Para poner fin a tan perjudiciales y nocivas prácticas, la comunidad internacional ha diseñado diferentes instrumentos, con los cuales se ha conminado a los países a adoptar en sus legislaciones internas fórmulas educativas y sancionatorias severas para eliminar ese tipo de actos y toda forma de discriminación. Así se ha estatuido, entre otros, en la Declaración sobre la Eliminación de la Violencia contra la Mujer (art. 4, literal d), y en la Convención Interamericana para Prevenir, Sancionar y Erradicar la Violencia contra La Mujer "Convención de Belém do Pará" (art. 7, literal g)".

\section{CONCLUSIONES}

La globalización del derecho ha desplazado la temática de los derechos humanos de la esfera exclusivamente estatal a una dimensión internacional. En cuanto a los derechos humanos del niño, la Corte Interamericana de Derechos Humanos ha desarrollado el concepto de corpus juris. Este está formado por un conjunto de instrumentos internacionales de contenido y efectos jurídicos distintos, así como las decisiones adoptadas por los órganos internacionales, tanto universales como regionales. Su existencia resulta de la evolución del Derecho Internacional de los Derechos Humanos en esta temática.

Se evidencia la existencia de un marco jurídico común en el Derecho Internacional de los Derechos Humanos y la interdependencia que existe en el ámbito internacional entre los distintos sistemas internacionales de protección de derechos. En el hemisferio americano, el Sistema Interamericano de Protección de los Derechos Humanos, compuesto por la Comisión Interamericana de Derechos Humanos y la Corte Interamericana de Derechos Humanos, es subsidiario y complementario de los sistemas judiciales nacionales. Es deber de los Estados Miembros de la Organización de los Estados Americanos (OEA) ratificar e implementar a nivel nacional todos los instrumentos interamericanos de promoción y protección de los derechos humanos, además de impulsar su conocimiento en todos los estamentos de la sociedad. Asimismo, la construcción de estándares jurídicos en el marco del sistema interamericano debe complementarse con los esfuerzos de los Estados para ponerlos en práctica.

La Corte Interamericana de Derechos Humanos ha desarrollado el control de convencionalidad en la jurisprudencia interamericana, herramienta eficaz para la aplicación del Derecho Internacional de los Derechos Humanos en el ámbito interno. La protección de los derechos humanos del niño adquiere una materialización real mediante el diálogo jurisprudencial entre los mecanismos internacionales y regionales. A pesar de los avances alcanzados en materia legislativa respecto a la protección del niño, estos distan de ser palpables en la práctica. Aunque existen obligaciones que exigen el cumplimiento de los derechos humanos, la violencia hacia los niños continúa en todas las regiones del planeta, tanto en los países 
desarrollados como aquellos en vía de desarrollo.

La violencia contra los niños tiene múltiples facetas y sus consecuencias varían según su naturaleza; es necesario implementar un enfoque integrado y multisectorial para su prevención y eliminación. Eliminar y dar respuesta a la violencia hacia los niños es difícil en el contexto de la familia dado que esta es considerada la más privada de todas las esferas.

Los Estados tienen la obligación de adoptar todas las medidas legislativas, administrativas, sociales y educativas apropiadas para erradicar la violencia contra los niños. Tales medidas deben contener los siguientes elementos: un enfoque basado en los derechos del niño, las dimensiones de género de la violencia, prevención primaria, el papel central de la familia en las estrategias de cuidado y protección de los niños, factores de resiliencia y protección, circunstancias de riesgo, niños en situación de vulnerabilidad potencial, asignación de recursos, mecanismos de coordinación y rendición de cuentas.

Las acciones que se emprendan en aras de eliminar la violencia y específicamente la violencia intrafamiliar deben guiarse por los siguientes principios:

- La violencia contra los niños jamás es justificable.

- Toda violencia hacia los niños se puede prevenir.

- La vulnerabilidad de los niños a la violencia está relacionada con su edad y capacidad evolutiva.El principio del Estado de derecho debe aplicarse a los niños, en pie de igualdad con los adultos.

- Un planteamiento de la protección del niño, basado en la perspectiva de sus derechos, exige su reconocimiento como titular de derechos, con su personalidad propia, sus necesidades específicas, sus intereses y privacidad.

- En todos los procesos de toma de decisiones se debe respetar el derecho del niño a ser escuchado y a que sus opiniones se tengan en cuenta.

- El interés superior del niño debe ser una consideración primordial en todas las cuestiones que le conciernan o afecten, especialmente cuando sea víctima de actos de violencia, así como cuando se planeen medidas preventivas.

\section{REFERENCIAS}

Arendt, H. (1974). Los Orígenes del Totalitarismo. Madrid: Taurus.

Botero, C. y Guzmán, D. (2007). El Sistema de los Derechos. Bogotá D.C., Colombia: DeJusticia, Corte Constitucional. 
Comisión Interamericana de Derechos Humano. (5 de agosto de 2009). Informe sobre el castigo corporal y los Derechos Humanos de las niñas, niños $y$ adolescentes. Organización de los Estados Americanos. Relatoría sobre los Derechos de la Niñez, recuperado de: http://www.cidh. org/ninez/castigocorporal2009/castigocorporal.indice.htm

Comisión Interamericana de Derechos Humanos. (16 de abril de 2001). Informe Nro. 54/01: Caso 12.051 María de Penha Maia Fernandes. Organización de los Estados Americanos, recuperado de http:// www.cidh.oas.org/women/Brasil12.051.htm

Comité de los Derechos del Niño. (21 de agosto de 2006). Observación General No. 8, Comité de los Derechos Niño, El derecho del niño a la protección contra los castigos corporales y otras formas de castigo crueles o degradantes (artículo 19, párrafo 2 del artículo 28 y artículo 37, entre otros). Naciones Unidas, recuperado de http://hrlibrary.umn.edu/ $\mathrm{crc/spanish/Sgeneralcomment8.html}$

Comité para la Eliminación de la Discriminación contra la Mujer. (1989). Recomendación General Nro. 12. Organización de las Naciones Unidas para las Mujeres, recuperado de http://www.un.org/womenwatch/ daw/cedaw/recommendations/recomm-sp.htm

Comité para la Eliminación de la Discriminación contra la Mujer. (14 de noviembre de 2014). Recomendación general Nro. 31: Comité para la Eliminación de la Discriminación contra la Mujer y observación general núm. 18 del Comité de los Derechos del Niño sobre las prácticas nocivas, adoptadas de manera conjunta. Naciones Unidas, recuperado de https:// documents-dds-ny.un.org/doc/UNDOC/GEN/N14/627/81/PDF/ N1462781.pdf? OpenElement

Consejo de Derechos Humanos. (19 de abril de 2012). Resolución 19/37 aprobada por el Consejo de Derechos Humanos. Naciones Unidas, recuperado de http://srsg.violenceagainstchildren.org/sites/ default/files/documents/docs/A-HRC-RES-19-37_ES.pdf

Consejo de Europa. (Junio de 2008). Abolición del castigo físico infligido a niños y niñas. Council of Europe, recuperado de https://rm.coe. int/168046d0ab

Consejo de Europa. (2009). Una estrategia integral contra la violencia. Council of Europe, recuperado de https://rm.coe.int/168046eb7f

Convención sobre los Derechos del Niño. (Junio de 2006). Naciones Unidas, recuperado de http://www.un.org/es/events/childrenday/pdf/ derechos.pdf

Corte Constitucional de la República de Colombia. (11 de marzo de 2008). 
Sentencia C-256 [MP Manuel José Cepeda Espinosa]. Recuperado de http://www.corteconstitucional.gov.co/relatoria/2008/c-256-08. htm

Corte Constitucional de la República de Colombia. (14 de septiembre de 2016). Sentencia C-496 [MP María Victoría Calle Correa], Salvamento de Voto: [M. Alberto rojas Ríos]. Recuperado de http:// www.corteconstitucional.gov.co/relatoria/2016/C-496-16.htm

Corte Interamericana de Derechos Humanos. (28 de agosto de 2002). Opinión Consultativa: Condición Jurídica y Derechos Humanos del Niño. Corte Interamericana de Derechos Humanos, recuperado de http:// www.corteidh.or.cr/docs/opiniones/seriea_17_esp.pdf

Corte Interamericana de Derechos Humanos. (2015). Cuadernillo de Jurisprudencia de la Corte Interamericana de Derechos Humanos $N^{\circ} 7$. Corte Interamericana de Derechos Humanos, recuperado de http://www. corteidh.or.cr/sitios/libros/todos/docs/controlconvencionalidad8. pdf

Corte Interamericana de Derechos Humanos. (Mayo a agosto de 2016). Boletín Jurisprudencial de la Corte Interamericana de Derechos Humanos $N^{\circ}$ 6. Recuperado de http://www.corteidh.or.cr/sitios/libros/todos/ docs/boletin6spa.pdf

Departamento de Derecho Internacional - Organización de los Estados Americanos OEA. (7 al 22 de noviembre de 1969). Convención Americana sobre Derechos Humanos suscrita en la Conferencia Especializada Interamericana sobre Derechos Humanos (B-32). Recuperado http:// www.oas.org/dil/esp/tratados_B-32_Convencion_Americana sobre_Derechos_Humanos.htm

Departamento de Derecho Internacional - Organización de los Estados Americanos OEA. (17 de noviembre de 1988). Protocolo Adicional a la Convención Amaricana sobre Derechos Humanos en materia de Derechos Económicos, Sociales y Culturales "Protocolo de San Salvado". Recuperado de http://www.oas.org/juridico/spanish/Tratados/a-52.html

Departamento de Derecho Internacional - Organización de los Estados Americanos OEA. (09 de Junio de 1994). Convención Interamericana para prevenir, sancionar y erradicar la violencia contra la mujer "Convención de Belem Do Para". Recuperado de http://www.oas.org/juridico/ spanish/tratados/a-61.html

Diario El País. (11 de julio de 2017). Se elevan los casos de violencia intrafamiliar en Colombia: Medicina Legal. Recuperado de http://www. elpais.com.co/judicial/se-elevan-los-casos-violencia-intrafamiliaren-medicina-legal.html 
Fernández, A. (2010). La prevención del maltrato intrafamiliar a los niños. Bogotá, D.C.: Leyer.

Fondo de las Naciones Unidas para la Infancia. (5 de diciembre de 2016). Campaña Para cada niño, \#ENDviolence. Recuperado de https://www. unicef.org/spanish/endviolence/

Galvis, L. (2006). Las niñas, los niños y los adolescentes. Titulares activos de derechos. Bogotá, D.C.: Ediciones Aurora.

Global Initiative. (2017). La Iniciativa Global para Acabar con todo Castigo Corporal hacia los niños. Recuperado de http://www. endcorporalpunishment.org/prohibiting-corporal-punishment/ introduction.html

Naciones Unidos para los Derechos Humanos. (17 de abril de 2013). Observación general $N^{\circ}$ 15: El derecho del niño al disfrute del más alto nivel posible de salud (artículo 24). Recuperado de http://docstore.ohchr. org/SelfServices/FilesHandler.hx?enc $=6 \mathrm{QkG1d \% 2fPPRiCAqhK-}$ b7yhsqIkirKQZLK2M58RF\%2f5F0vHCIs1B9k1r3x0aA7FYrehlsj\%2fQwiEONVKEf8BnpvEXS17WLpnaEMIpupYgu9Jcq5Jn16KhXRgZtqhSh9BZY9KH

Oficina de la Representante Especial del Secretario General sobre la Violencia contra los Niños. (2017). Hacia un Mundo sin Violencia. Naciones Unidas, recuperado de http://srsg. violenceagainstchildren.org/sites/default/files/documents/docs/ hacia_un_mundo_sin_violencia_booklet.pdf

Oficina del Alto Comisionado de Naciones Unidas para los Derechos Humanos. (10 de Diciembre de 1948). La Declaración Universal de Derechos Humanos. Naciones Unidas, recuperado de http://www. ohchr.org/EN/UDHR/Documents/UDHR_Translations/spn.pdf

Oficina del Alto Comisionado de Naciones Unidas para los Derechos Humanos. (17 de abril de 2001). Observación General Nro. 1: Párrafo 1 del Artículo 29: Propósitos de la Educación. Recuperado de http:// tbinternet.ohchr.org/_layouts/treatybodyexternal/Download. aspx? symbolno $=\mathrm{CRC} \% 2 \mathrm{fGC} \% 2 \mathrm{f} 2001 \% 2 \mathrm{f} 1 \& \mathrm{Lang}=\mathrm{en}$

Oficina del Alto Comisionado de Naciones Unidas para los Derechos Humanos. (27 de noviembre de 2003). Observación General No. 5: Medidas generales de aplicación de la Convención sobre los Derechos del Niño (artículos 4 y 42 y párrafo 6 del artículo 44). Naciones Unidas, recuperado de http://docstore.ohchr.org/SelfServices/FilesHandler.ashx? enc $=6 \mathrm{QkG} 1 \mathrm{~d} \% 2 \mathrm{fPPRiCAqhKb} 7 \mathrm{yhsiQq18gX5Zxh0c-}$ QqSRzx6Zd2\%2fQRsDnCTcaruSeZhPr2vZQMqmhlfEo7plKbViUohP68AqgUKSq8kLJXMNTlpf9VZbzCJMclV3cDztYhaQ2op 
Oficina del Alto Comisionado de Naciones Unidas para los Derechos Humanos. (21 de agosto de 2006). Observación general No. 8: El derecho del niño a la protección contra los castigos corporales y otras formas de castigo crueles o degradantes (artículo 19, párrafo 2 del artículo 28 y artículo 37, entre otros). Naciones Unidas, recuperado de http://docstore.ohchr.org/ SelfServices/FilesHandler.ashx?enc $=6 \mathrm{QkG1d} \% 2 \mathrm{fPPRiCAqhKb7y-}$ hsqIkirKQZLK2M58RF\%2f5F0vF1b6rTFNjw4eY3W5adlOuDmaWHHv5SI\%2fmE3GtxI20VC8CAhXwC\%2fSDnNTm9RZu7N5JNQtqDY5SB0dLtbePmPNff

Oficina del Alto Comisionado de Naciones Unidas para los Derechos Humanos. (20 de julio de 2009). Observación General No. 12: El derecho del niño a ser escuchado. Naciones Unidas, recuperado de http://docstore.ohchr.org/SelfServices/FilesHandler. ashx? enc $=6 \mathrm{QkG} 1 \mathrm{~d} \% 2 \mathrm{fPPRiCAqhKb} 7 \mathrm{yhsqI}$ irirKQZLK2M58RF\%2f5F0vHKTUsoHNPBW0noZpSp5d6MOecQAKeVQ5zIMW6E4Msxs4Ov3WZi2aEiJFXmn2EhSht8EgbO6IqGP47JXUhcPIP4

Oficina del Alto Comisionado de Naciones Unidas para los Derechos Humanos. (2017). Consejo de Derechos Humanos. Naciones Unidas, recuperado de http://www.ohchr.org/SP/HRBodies/HRC/Pages/ HRCIndex.aspx

Organización de las Naciones Unidas para las Mujeres. (1992). Recomendación General Nro. 19: Violencia contra la Mujer. Comité para la Eliminación de la Discriminación contra la Mujer, recuperado de http://www.un.org/womenwatch/daw/cedaw/recommendations/ recomm-sp.htm

Organización de las Naciones Unidas para los Derechos Humanos. (18 de abril de 2011). Convención sobre los Derechos del Niño: Observación general $N^{o}$ 13: Derecho del niño a no ser objeto de ninguna forma de violencia. Recuperado de http://www2.ohchr.org/english/bodies/crc/docs/ CRC.C.GC.13_sp.pdf

Organización de las Naciones Unidas para los Derechos Humanos. (29 de mayo de 2013). Convención sobre los Derechos del Niño: Observación general $N^{o} 14$ - El derecho del niño a que su interés superior sea una consideración primordial (artículo 3, párrafo 1). Recuperado de http://www. unicef.cl/web/informes/derechos_nino/14.pdf

Organización de Naciones Unidas. (04 de abril de 2012). Resolución 66/141 aprobada por la Asamblea General. Recuperado de http:// srsg.violenceagainstchildren.org/sites/default/files/documents/ docs/A_RES_66_141_Esp.pdf 
Organización de Naciones Unidas. (12 de abril de 2013). Resolución 67/152 aprobada por la Asamblea General. Recuperado de http:// srsg.violenceagainstchildren.org/sites/default/files/documents/ docs/A_67_152_Esp_0.pdf

Organización Mundial de la Salud - OMS. (28 de septiembre de 2017). Preguntas más frecuentes. Recuperado de http://www.who.int/suggestions/faq/es/

Órganos de las Naciones Unidas. (10 de abril de 1992). Observación General 20 al Artículo 7 del Pacto Internacional de Derechos Civiles y Políticos. Recuperado de http://www.hchr.org.co/documentoseinformes/documentos/html/informes/onu/cdedh/Observacion\%20Gral.\%20 \%2020\%20Art\%207\%20PDCP.html

Red Internacional para los Derechos Económicos, Sociales y Culturales. (Noviembre de 1999). Observación general $N^{o}$ 13: El derecho a la educación (artículo 13). Recuperado de https://www.escr-net.org/es/recursos/observacion-general-no-13-derecho-educacion-articulo-13

Representante Especial del Secretario General de las Naciones Unidas sobre la violencia contra los niños. (2010-2014). Informe Anual de la Asamblea General sobre la violencia contra los niños. Naciones Unidas, recuperado de http://srsg.violenceagainstchildren.org/es/category/document-type/srsg-reports

Representante Especial del Secretario General sobre la Violencia contra los Niños. (16 de marzo de 2017). Violencia contra los Niños. Naciones Unidas, recuperado de http://srsg.violenceagainstchildren. org/es

Save the Children. (19 de noviembre de 2015). Campaña Cambio de actitudes: 'No quieres que te vean así. Recuperado de https://resourcecentre. savethechildren.net/library/changing-attitudes-no-quieres-que-tevean-asi 